\title{
Empirical Analysis on Coordination of Hubei Province Transportation
}

\author{
and Economy \\ Xiuping $\mathrm{He}^{*}$ \\ School of business Huanggang normal university, China. \\ *Corresponding author:Xiuping He,MBA,27730070@qq.com
}

\begin{abstract}
This paper uses the time series data and set up the econometric models, empirical analyse the coordination of comprehensive transportation and economy according to the unit root test and cointegration test and Grant test in Hubei Province, we can infer that Hubei Province comprehensive transportation system showed no transportation to promote the role of regional economic growth. and puts forward the corresponding countermeasures according to the analytical results.
\end{abstract}

Key words: Hubei; transportation; economy; coordination

\section{Introduction}

Hubei Province,as a central region of the rapid economic growth of the province, its transportation and economic development in the rapid development of traffic supply capacity greatly improved at the same time, the economy is also in the two digit rate of rapid growth.According to theoretical analysis, it can be concluded that the modern transportation and economic growth in Hubei is also coordinated development,but the relationship between economic growth and development of traffic supply capacity is consistent with the theoretical analysis has not been confirmed.Whether the traffic supply capacity increasing leads to economic growth or the rapid growth of economy leads to the increase of traffic supply capacity,or traffic supply capacity and economic growth is mutual promotion.This paper is based on econometric analysis to demonstrate the comprehensive transportation and economic coordination in Hubei Province.

\section{Experimental}

\subsection{Unit Root Test}

Time series analysis required sample size cannot be too little.In the index selection, therefore, should not only consider indicators representative meaning, also want to consider index can be obtained and the sample size.This paper studies Hubei Province transportation system and the coordination of regional economic system from two aspects.First,reflect the promoting effect of transportation on regional economy,select GDP as an index of the dependent variable.Select freight volume (FV), passenger volume (PV) as independent variable index to 
Table1 FV first order difference of unit root test results

\begin{tabular}{|l|c|c|c|c|}
\hline \multicolumn{2}{|l|}{ Null Hypothesis: D(FV) has a unit root } & & t-Statistic & Prob.* \\
\hline & & & -2.843739 & 0.0072 \\
\hline Augmented Dickey-Fuller test statistic & & -2.699769 & \\
\hline Test critical values: & $1 \%$ level & & -1.961409 & \\
\hline & $5 \%$ level & & -1.606610 & \\
\hline & $10 \%$ level & & & \\
\hline
\end{tabular}

Table2 PV first order difference of unit root test results

\begin{tabular}{|l|c|c|c|c|}
\hline \multicolumn{2}{|l|}{ Null Hypothesis: D(PV) has a unit root } & & t-Statistic & Prob. $^{*}$ \\
\hline & & -3.404440 & 0.0019 \\
\hline Augmented Dickey-Fuller test statistic & & -2.699769 & \\
\hline Test critical values: & $1 \%$ level & & -1.961409 & \\
\hline & $5 \%$ level & & -1.606610 & \\
\hline & $10 \%$ level & & - & \\
\hline
\end{tabular}

Table3 InZGDP first order difference of unit root test results

\begin{tabular}{|c|c|l|l|l|}
\hline \multicolumn{4}{|c|}{ Null Hypothesis: D(ZGDP) has a unit root } & \\
\hline & & & t-Statistic & Prob. $^{*}$ \\
\hline \multicolumn{2}{|c|}{ Augmented Dickey-Fuller test statistic } & -1.940769 & 0.0521 \\
\hline Test critical values: & $1 \%$ level & & -2.699769 & \\
\hline & $5 \%$ level & & -1.961409 & \\
\hline & $10 \%$ level & & -1.606610 & \\
\hline
\end{tabular}

study the impact of the transportation industry on the economy and the amount of people's lives services to GDP.Second,reflect the regional economic support for the transportation.The selected dependent variable indexes:Turnover of goods $F(T)$,Passenger turnover (PT).The selected independent variable indexes:GDP,Transportation fixed asset investment (TI).To reflect regional economic direct input to the transportation system--transportation fixed asset investment and Induced Investment--the impact of GDP on the production of traffic and transportation industry.Through the analysis of both promote and support relationship,to study the coordinated development of the two systems and their mutual promotion and common development.This study cointegration study index sample in the range of 1991 to 2010 (data resources: Hubei statistical yearbook). To get rid of price change on the influence of GDP,this paper use in each of the commodity retail price index(last year is 100).Get converted to GDP in 1978,expense ZGDP.In order to remove the dimension and the sequence of the heteroscedasticity, and obtain more economic sense as a result.In this paper, the natural 
logarithm of ZGDP, FV, FT, PV, PT, TI is obtained,expense InZGDP, InFV, InFT, InPV, InPT and InZTI.In this paper, the analysis of the research work is based on econometric software Eviews6.0.

Using econometric software Eviews6.0 on InzGDP respectively, InFV and InPV unit root test1,Results show that the above three variables ZGDP, PV and the logarithm of FV there are unit root, so they are stationary time series,Below we will do with three variables of first order difference of unit root test.The results show in table 1, table 2 and table 3 .

From the point of test results, in $1 \%, 5 \%$ and $10 \%$ under the three significant levels of unit root test are smaller than the corresponding critical value, so as to reject the null hypothesis. Show that Hubei gross national product (GNP),Select freight volume(FV) and passenger volume (PV) difference series, there is no unit root is stationary series.In order to analyze whether there is a co-integration relationship between freight volume(FV),passenger volume (PV)and GDP growth,We first make the return of the passenger volume and GDP between two variables, and then test the stationarity of the regression residuals.

\subsection{Co-integration test}

Below using econometric analysis methods to analyze the relationship of Hubei Province transportation supply ability of granger causality test and economic growth.In previous studies, when doing co-integration of traffic and economic system,we usually use the freight volume and passenger volume as the independent variable,the GDP as the dependent variable to demonstrate co-integration relationship.But in fact, passenger and cargo's homework is not the same of the economy.Therefore, this paper will be separated from the freight volume and passenger volume and economic indicators to carry out a co-integration analysis2.According to the results of stability analysis of time series,we can see that passenger volume and GDP index are both a non-stationary time series. In view of the non-stationary time series, co-integration test must be conducted in order to avoid the wrong results are obtained before the regression analysis and granger causality test.This paper choose popular Johansen co-integration test method3,Co-integration test on two variables of freight volume and economic growth GDP in Hubei Province.With Eviews econometric analysis software,result shows in table4:

Table 4 Johansen Co-integration relationship between freight volume and GDP

\begin{tabular}{|l|l|l|l|l|}
\hline Hypothesized & & Trace & 0.05 & \\
\hline No. of CE(s) & Eigenvalue & Statistic & Critical Value & Prob.** \\
\hline None $*$ & 0.527807 & 17.19375 & 15.49471 & 0.0275 \\
\hline At most $1 *$ & 0.229742 & 4.437514 & 3.841466 & 0.0351 \\
\hline \multicolumn{5}{|l}{ Trace test indicates 2 cointegrating eqn(s) at the 0.05 level } \\
\hline$*$ denotes rejection of the hypothesis at the 0.05 level \\
\hline **MacKinnon-Haug-Michelis (1999) p-values \\
\hline
\end{tabular}


From the above Johansen test,we can conclude two collaborators the whole relationship between freight volume and GDP in Hubei Province.This suggests there is a long-term stable relationship between the Hubei freight volume and GDP.

Below co-integration test on two variables of freight volume and economic growth GDP in Hubei Province.With Eviews econometric analysis software,result shows in table5:

Table5 Co-integration test results of freight volume and economic growth in Hubei Province

\begin{tabular}{|l|l|l|l|l|}
\hline Hypothesized & & Trace & 0.05 & \\
\hline No. of CE(s) & Eigenvalue & Statistic & Critical Value & Prob.** \\
\hline None & 0.532260 & 14.83700 & 15.49471 & 0.6218 \\
\hline
\end{tabular}

From the above test results,we can see that the critical value of $5 \%$ significant level,the statistical value is less than the critical value,so we do not reject the original hypothesis.There is no long-term stable relationship between the amount of passenger traffic and GDP in Hubei province.

\subsection{Granger causality test}

Known from the analysis of last section,there is a long-term and stable relationship between InzGDP and InFV,There is no long-term equilibrium relationship between InzGDP and InPV.,this section studies whether there is a causal relationship between them.Because of InZGDP, InFV and I are all InPV (1) sequences,are all non-stationary series, Therefore needs to be non-stationary sequence stabilization.Choose its first order differential sequence,Gnarge causality test for the lag order of 1.result shows in table6 and table7:

Table $6 \quad$ Granger causality test between InPV and InzGDP
\begin{tabular}{|l|l|l|l|}
\hline Pairwise Granger Causality Tests & Obs & F-Statistic & Prob. \\
\hline Null Hypothesis: & 18 & 0.43264 & 0.6578 \\
\hline PV does not Granger Cause ZGDP & & 5.88228 & 0.0152 \\
\hline ZGDP does not Granger Cause PV
\end{tabular}

Table 7 Granger causality test between InFV and InzGDP

\begin{tabular}{|l|l|l|l|}
\hline Pairwise Granger Causality Tests & Obs & F-Statistic & Prob. \\
\hline Null Hypothesis: & 18 & 0.97723 & 0.4024 \\
\hline FV does not Granger Cause ZGDP & & 5.20521 & 0.0219 \\
\hline ZGDP does not Granger Cause FV
\end{tabular}

\section{Results and Discussion}

From the above causality test can be seen that the rapid economic development in Hubei Province is bound to bring about the growth of passenger volume and freight volume, that is, there is a causal relationship between GDP and passenger volume and freight volume.Passenger volume growth is not the cause of GDP growth, there is no causal 
relationship between the amount of GDP and passenger traffic.From the test results, the causal relationship between freight volume and GDP can not reject the original hypothesis, freight volume is not the reason for the growth of GDP.But from a specific point of view, $\mathrm{P}$ value is only 0.4024 , not very significant.It can be considered that there is a certain causal relationship between freight volume and GDP, but not very obvious.Combined with the results obtained from the last section, there is no long-term equilibrium relationship between the freight volume and passenger volume and the GDP.So we can infer that Hubei Province comprehensive transportation system showed no transportation to promote the role of regional economic growth.

\section{Analysis and conclusion}

Above using econometric model, co-integration analysis and Granger causality analysis of the coordination of the Hubei provincial comprehensive transportation system and economy system,we can see that the rapid growth of economy of Hubei Province on transportation infrastructure and freight and passenger volume increase is significant,but the effect of transportation on economic growth is not significant.This shows that in the rapid economic growth in Hubei Province,while the transportation network is gradually perfect and the transportation supply ability constantly improve,the improvement of traffic supply capacity did not play a significant role in promoting economic growth.It is the rapid economic growth that has brought the improvement of the transportation network and the improvement of the transportation capacity.

The improvement of the supply ability of modern transportation not only needs the improvement of modern transportation system, but also the improvement of modern transportation information system is an indispensable part of improving the ability of transportation.Using only the degree of perfection of Hubei modern transportation infrastructure network to measure the level of modern transportation supply capacity,to transport in play a role in promoting economic growth is not comprehensive enough.Modern transportation system and information system is two indispensable support platform to the development of modern traffic.The promoting effect of the development level of modern traffic on economic growth depends on the perfection of the two modern transportation infrastructure platform.Therefore, in improving the transportation network, we should also strengthen the improvement of the transportation information system.Low level of traffic information is also a bottleneck restricting the development of modern transportation in Hubei Province,makes the modern transportation of promoting effect on economic growth in hubei province has not been played out.

Grasping the idea of modern traffic management,promoting the implementation of the modern traffic management mode of operation and being widely applied to all kinds of transportation management technology are also an effective way to improve the supply capacity of modern transport in Hubei province.The improvement of transport hardware facilities can only 
provide the prerequisite for the improvement of the ability of transportation supply.To truly improve the supply ability of modern transportation, it is also required to study modern traffic management concept and modern management technology.However, the education level of transportation industry practitioners is generally low, and the lack of management concept is also an important reason for restricting the improvement of modern transportation supply capacity.Therefore, in order to further promote the modern traffic, so that the development of transportation and economic coordination.To improve the education level of modern transportation workers, the study and application of modern transportation management concept is also a concern of the government and people of all walks of life.

\section{References}

1. D.H. Yi, Data analysis and Eviews application [M]. Beijing: China Renmin University Press.2008.str.169-197

2. H. Pang, Econometrics [M]. Beijing: Science Press.2010.str.88-103

3. J.S. Sun,. Study guide and Eviews Application guide [M]. Beijing: Tsinghua University press, 2010 .str.265-323

4. X.K. Wang, Research on coordinated development of comprehensive transportation compound system. Shaanxi: Chang'an University, 2003

5. C.J. Xiong, X.X. Ning, The coordinated development of the comprehensive transportation Chinese each transportation mode evaluation research of [J]. system engineering, 2006

6. A.G. Li, On the development of modern logistics and comprehensive transportation [J]. integrated transport.2006.3 